\title{
Editors Desk
}

\section{Warm greetings,}

Learning is a continuous phenomenon with limitless boundaries. This is especially true in the field of Dental sciences, with concepts and technologies of yester years being replaced by entirely new ones today. Hence, it is important for us to regularly update ourselves with this knowledge, for the benefit of both professionals and patients.

Each issue of this journal has exhibited articles and papers dealing with all aspects of dentistry presented in a very lucid manner. We sincerely admire the exemplary efforts of the previous editor and we would like to join the editorial board of the journal in thanking the past editor-in-chief for her service to our readers.

To carry forward the process of growth of this journal, we are aspiring and conjuring up efforts to be a PubMed indexed journal in Dentistry. To improve the current status, we would hope to receive high quality manuscript from all authors. Papers are welcome in multiple areas and especially those in which novelty is portrayed well. I hope that your publication in this journal will benefit all readers and you as well.

\section{Thank You.}

\section{Best Wishes}

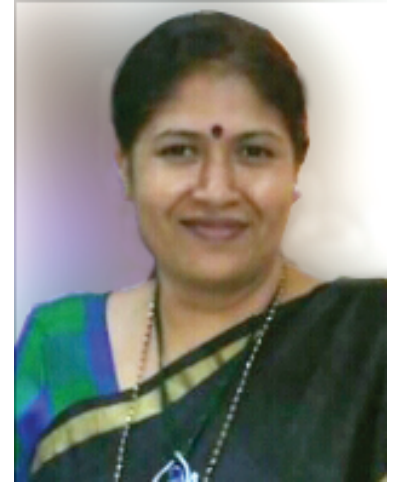

Dr. Vandana K.L Editor-in-Chief

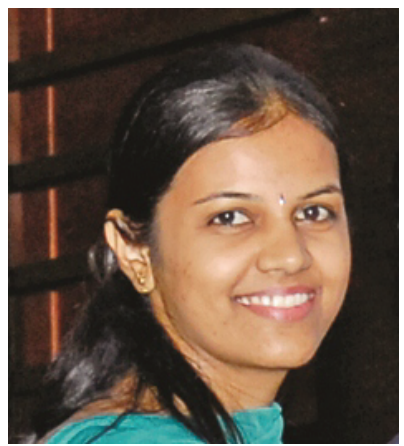

Dr. Nagaveni N.B Associate Editor

How to site this article:

Vandana K.L. , Nagaveni N.B, Editors Desk. CODS J Dent 2015;7: 03

Source of support : Nil. Conflict of interest: None Declared 